\title{
Early sexual debut and risky sex in young adults: the role of low self-control
}

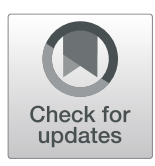

\author{
B. M. Magnusson ${ }^{*}$, A. Crandall and K. Evans
}

\begin{abstract}
Background: The purpose of this study was to examine the role of low self-control as a mediator or moderator between early age at sexual debut and risky sexual behavior in young adulthood.

Methods: Data on 5734 male and female Add Health participants were used. Self-control (waves 1 \& 3), age at sexual debut (wave 3) and risky sexual behavior (wave 4) were used in a structural equation modeling framework to assess the relationships of interest.

Results: Approximately $17 \%$ of respondents were $<15$ years at first sexual intercourse. Among females only, both early age at first intercourse (Parent-report: $z=5.08, p<.001$; Self-report: $z=2.05, p<.05$ ) and low self-control at wave 3 (Parent-report: $z=2.30, p<.05$; Self-report: $z=2.31, p<.05$ ) mediated the relationship between low selfcontrol at wave 1 and risky sexual behaviors in young adulthood. Similarly in the male-only model, both early age at first intercourse (Parent-report: $z=2.92, p<.01$; Self-report: $z=3.04, p<.01$ ) and low self-control at wave 3 (Parentreport: $z=1.99, p<.05$; Self-report: $z=3.15, p<.01)$ mediated the relationship between low self-control and risky sexual behaviors in young adulthood. There was evidence of moderation in the male-only model $(-0.26, p<.01)$, such that lower impulsivity strengthened the relationship between early sex and risky sex.

Conclusions: This study confirms the role of executive functions in sexual behaviors and suggests that interventions aimed at improving self-control may be beneficial in reducing risky sexual behavior.
\end{abstract}

Keywords: Sexual behavior, Self-control, Executive function, Sexual debut, Sexual initiation

\section{Background}

The onset of sexual activity during adolescence is a normative developmental milestone. By age 19, nearly $70 \%$ of both males and females report ever having had sexual intercourse [1]. However, sexual debut occurring at an earlier than normative age (typically $<15$ years) is associated with engagement in risky sexual behaviors in adolescence and throughout adulthood. Early sexual experience is associated with increased rates of sexually transmitted infections [2], more sexual partners [3], inconsistent use of contraceptives [4], unintended pregnancy [5], concurrency, and sex with risky partners [6] in adulthood. An estimated 16\% of US adolescents have had vaginal intercourse by their 15th birthday [7]. The probability of early sexual debut differs by sex and race/ ethnicity. For all races, males have a higher probability

\footnotetext{
* Correspondence: brianna_magnusson@byu.edu

Department of Public Health, Brigham Young University, 4103 LSB, Provo, UT
} 84602, USA

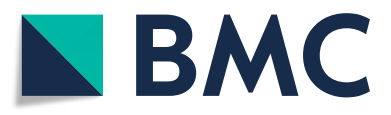

(c) The Author(s). 2019 Open Access This article is distributed under the terms of the Creative Commons Attribution 4.0 International License (http://creativecommons.org/licenses/by/4.0/), which permits unrestricted use, distribution, and reproduction in any medium, provided you give appropriate credit to the original author(s) and the source, provide a link to the Creative Commons license, and indicate if changes were made. The Creative Commons Public Domain Dedication waiver (http://creativecommons.org/publicdomain/zero/1.0/) applies to the data made available in this article, unless otherwise stated. panic youths have a higher probability of early debut than their White and Asian counterparts [8]. While decades of research have linked early debut with risky behaviors, the mechanism of action is not fully understood.

It is suggested that low self-control (e.g. impulsivity or low inhibitory control) may explain the association between timing of sexual debut and risky sexual behavior. Low self-control, specifically impulsivity, has been associated with early sexual initiation [9] and with risky sexual behaviors, including sex while intoxicated, infrequent use of condoms, engaging in sex with strangers, having multiple partners and a history of sexually transmitted disease (STD) $[10,11]$. It is suggested that low self-control in adolescence, at least partially, explains selection into early sex [9]. It is further hypothesized that low selfcontrol, present in adolescence, may persist throughout adulthood continuing to influence involvement in risky 
sexual behaviors and possibly compounding the effects of early sex on later risky sex.

Gender differences in the development of executive functions and the timing and social acceptance of sexual activity exist. For example, girls on average develop more advanced executive functioning skills 1-2 years earlier than males during adolescence [12]. In general males have lower levels of impulse control and higher levels of sensation seeking [13]. Additionally, the level of impulsive behavior [14] and the influence of impulsivity on specific health behaviors may vary by gender [15]. Sexual scripting theory is the application of social scripts to sexual behavior [16]. Sexual scripts, specify the acceptability of sexual behavior in specific times, places, and circumstance and provide individuals acting within those scripts with guidelines for acceptable expression of sexuality. Within Western cultures, social scripts related to sexuality differ markedly by gender, a so-called "sexual double-standard" [17]. These scripts are generally more accepting of sexual expression for males than for females. Consistent with sexual scripting, across all races and ethnicities, US males have a higher probability of early sexual initiation [8]. Social expectations promote sexual expression and behavior for males and restrict sexual expression and behaviors for females. Specifically, a 2016 study examining peer acceptance surrounding sexual initiation observed that females pay a social penalty in terms of peer acceptance over time for engaging in sex, while males receive a social reward in peer acceptance for engaging in sex [18]. Research has also shown that among emerging adults, women perceive that their gender affects their thoughts and feelings about sex [19]. These gendered norms, suggest that it is important to evaluate whether any role of impulsivity in the associations between early sexual debut and risky sexual behavior in adulthood differs by gender.

\section{Theoretical model and aims}

Social Cognitive Theory (SCT) serves as the theoretical basis for this study [20]. SCT proposes that a person's capacity to self-regulate influences has a significant effect on their behavior. Based on this theory, we would expect that impulsivity/low self-control would be strongly predictive of a younger age at first sex and later engagement in risky sexual behaviors. Further, we would expect that the association between early sex and later risky sexual behaviors would be weaker among those who develop better impulse control (less impulsivity) than among those who are more impulsive. The purposes of this study are 1) to examine the effect of low self-control and impulsivity on early sexual debut and risky sexual behavior in adulthood and 2) to determine if these relationships vary by gender.
We hypothesized that low self-control in wave 1 would be associated with early age at sexual debut in wave 3 and that low self-control in wave 3 would be associated with risky sexual behavior in wave 4 . We expected that we would observe persistence of low self-control over time such that low self-control in wave 1 would be predictive of impulsivity at wave 3 . Additionally, we hypothesized that early age at sexual debut would mediate the relationship between low self-control at wave 1 and risky sexual behavior in wave 4 . We further hypothesized, that low self-control in wave 3 would moderate the relationship between early sex and risky sexual behavior such that the relationship between early age at sexual debut and risky sexual behaviors would be stronger among those with lower self-control. Finally, we hypothesized that these relationships may vary by gender.

The purpose of this study is to examine self-control as a mechanism of action that may partially explain the observed associations between early sexual initiation and sexual risk taking in adulthood. The plurality of the extant research on the relationship between early sexual experience and risky sexual behaviors has examined sexual risk taking that is more proximal to sexual initiation (e.g. condomless sex in adolescence). Although research does identify associations between early sexual experience and sexual risk taking in adulthood, most of these studies have relied on cross-sectional data. Few longitudinal datasets exist which span the entire period from early adolescence into adulthood. The National Longitudinal Study of Adolescent to Adult (Add) Health, used for this study, allows for measurement of self-control preceding sexual initiation and before measuring adult sexual experience. Additionally, we used structural equation modeling to analyze the data, allowing us to examine multiple pathways simultaneously.

\section{Methods}

Data for 3032 female and 2702 male participants from three waves of The National Longitudinal Study of Adolescent to Adult ( $A d d$ ) Health were used for this study [21]. Add Health is an ongoing study that began in the mid-1990s with a nationally representative sample of students in grades 7-12. Four waves of data collection were completed between 1995 and 2007-2008. Add Health collects a wide range of data to assess the relationships between behavior and environment with health. We included data from waves 1,3 , and 4 in our analysis. Respondent's for whom age at first sex was missing at wave 3 were excluded from the analysis.

\section{Measures}

The analytic measures included self-control at two time points, early sexual initiation and risky sexual behavior in adulthood as delineated in the subsequent paragraphs. 
All constructs were derived from data in waves 1,3 and 4 of Add Health.

\section{Self-control}

Measures of self-control were modeled after the approach of Beaver, Ratchford \& Ferguson [22]. Two measures of low self-control in wave one were used 1) parent report of adolescent low self-control and 2) adolescent self-report of low self-control. Parent report of adolescent low self-control was comprised of four questions (e.g., "Does your child have a bad temper?"). Adolescent self-report of low self-control included four questions inquiring about difficulty paying attention, completing homework and getting along with teachers and peers (e.g., "Do you have trouble paying attention in school?"). For both the parent and adolescent report, higher scores indicated lower self-control in the adolescent. In wave 3 , low self-control was measured using ten items self-reported by the adolescent. Sample items include "You like to take risks," and "You often try new things just for fun or thrills, even if most people think they are a waste of time." All items were measured on a five-point Likert scale with higher values indicating lower self-control.

\section{Early sexual debut}

Early sexual debut was measured in wave three to give sufficient time for the youngest Add Health respondents to age beyond the timing for normative sexual debut. Respondents who reported they had ever had sexual intercourse were asked, "How old were you the first time you ever had vaginal intercourse". Early sexual debut was defined as first vaginal intercourse at prior to 15 years of age $[4,23,24]$.

\section{Risky sexual behavior}

Risky sexual behavior in early adulthood was measured using the three available items from wave four when Add Health respondents were 24 to 32 years of age. The items include "Total number of male and female partners in the past 12 months," "In the past 12 months have you paid someone for sex?" and "In the past 12 months have you had sex with more than one person at about the same time?"

\section{Controls}

We controlled for sex, age, race, wave one socio-economic stress, wave four socio-economic stress, and wave four relationship status, including married, cohabitating, dating, and single. Wave 1 socio-economic stress was a composite variable consisting of whether or not the participant's primary responding parent was married, whether or not the family was receiving public assistance, and parent education status. Wave 4 socio-economic stress was comprised of respondent's educational status, whether or not the participant owned a home, and whether the respondent could meet their basic needs.

Analytic strategy Data were cleaned and prepared in SAS (ver 9.4, SAS Institute Inc., Cary, NC, USA). Frequencies and proportions were calculated to describe the sample. We conducted confirmatory factor analysis (CFA) for each construct of interest with more than two items (waves 1 \& 3 self-control and wave 4 risky sexual behavior) in a structural equation modeling (SEM) framework using Mplus Version 7 (Muthén \& Muthén, 1998-2012). Items with factor loadings $<0.40$ were dropped. We assessed model fit using the following fit indices and cut-offs: Comparative Fit Index (CFI) $\geq 0.95$ indicated good fit and $<0.90$ indicated poor fit; Root Mean Square Error of Approximation (RMSEA) $\leq 0.06$ indicated good fit and $>0.10$ indicated poor fit [25].

After defining the measurement model, we used SEM to assess the relationships of interest. SEM is preferable over traditional longitudinal regression analyses because it accounts for measurement error and allows multiple relationships to be measured simultaneously. It is also an ideal approach for testing mediation and moderation. We fit a base model using early sexual debut and selfcontrol (wave 3) as predictors of risky sexual behavior (wave 4), while controlling for the effects of prior selfcontrol (wave 1). After fitting the base model, sociodemographic control variables were added to the model.

We next constructed a mediation model to examine whether early sexual debut and wave 3 self-control mediated the relationship between low self-control at baseline (wave 1) and risky sexual behavior (wave 4). Mediation was assesed by examining the significance of indirect effects using 5000 bootstraps [26]. Following the test for mediation, we created an interaction term between self-control (wave 3) and risky sexual behavior (wave 4) to examine whether self-control moderated the relationship between early sexual debut and later risky sexual behavior.

Finally, we sought to determine if the associations observed in the baseline, mediation and moderation models were different for males and females. We began by assessing measurement invariance for both selfcontrol (wave 3) and risky sexual behavior (wave 4) by testing for uniform differential item functioning (DIF) $[27,28]$. DIF indicates that at the same underlying level of self-control or early sex, women scored significantly different than expected compared to men on individual items and the difference was uniform. To examine DIF, we regressed the latent wave 3 self-control and risky sex constructs on gender, and looked for modification indices for individual items (that comprised the wave 3 selfcontrol and risky sex scales) on gender that were $\geq 4.0$. 
If there were modification indices above 4.0, these regression paths were added to the model in stepwise fashion and a chi-square difference test was performed. If the model paths and chi-square difference test were significant, there was evidence of DIF. We adjusted our models for significant differences found for any of the item indicators to ensure that any differences in model relationships observed between males and females were not attributable to DIF.

Because there was evidence that the wave 3 selfcontrol construct was not invariant across genders, we did not test whether the final models significantly varied by gender. Instead, we ran separate final models for males and females to understand the key model relationships for each gender, though we cannot statistically compare these models by gender.

We used the same fit indices and cutoffs for model fit of the structural models as we did for confirmatory factor analyses. In all models, we accounted for the complex survey design (probably weights and clustering). We used the robust weighted least squares maximum likelihood estimator, which is appropriate for data with categorical indicators, to estimate all models. Missing data were addressed using Full Information Maximum Likelihood (FIML).

\section{Results}

\section{Descriptive data}

The sample was comprised of 5734 persons and was $53 \%$ female. The average age of all respondents at wave 1 was 16 years old. The majority of respondents were white (58.5\%). Approximately $17 \%$ of respondents reported they were less than 15 years of age at first sexual intercourse. Sample demographics by sex are reported in Table 1.

\section{Measurement model}

We created latent variables for risky sexual behavior (wave 4) (factor loadings ranging from 0.61 to 0.91 ), low self-control (wave 3) (factor loadings ranging from 0.43 to 0.73 ), baseline low self-Control - self-report (wave 1; factor loadings ranging from 0.56 to 0.79 ), and baseline low self-control - parent report (wave 1; factor loadings ranging from 0.55 to 0.75 ). Model fit indices were all above the minimum cutoffs.

\section{Mediation mode}

Figure 1 includes the results of the mediation model for the full sample (Model Fit: RMSEA $=0.03, \mathrm{CFI}=0.92$ ). Early sexual debut $(0.26, p<.001)$ and wave 3 low selfcontrol $(0.17, p<.001)$ both predicted risky sexual behavior in wave 4 . Both adolescent self-report and parent report of baseline low self-control (wave 1) predicted higher likelihood of engaging in early sex and lower self- control at wave 3. Early sexual debut mediated the relationship between wave 1 self-report low self-control and wave 4 risky sex $(z=4.14, p<.001)$ and between wave 1 parent report of adolescent self-control and wave 4 risky sex $(z=6.07, p<.001)$. Wave 3 self-control mediated the relationship between wave 1 self-report low self-control and wave 4 risky sex $(z=4.16, p<.001)$ and between wave 1 parent report of adolescent self-control and wave 4 risky $\operatorname{sex}(z=3.54, p<.001)$.

\section{Moderation model}

We next added an interaction term to the model to assess if wave 3 self-control moderated the relationship between early sexual debut and later risky sexual behaviors (Fig. 2). In the full sample, there was evidence of a moderating effect. Unexpectedly, the relationship between early sexual debut and later risky sexual behaviors was stronger among those with higher self-control (wave 3) compared to those who reported lower self-control ($0.13, p<.05)$.

\section{Results by gender}

For both males and females, early sexual debut and selfcontrol (wave 3) mediated the relationship between baseline low self-control and later risky sexual behaviors. In the female only model, early sex mediated the relationship between parent report of adolescent low selfcontrol and risky sex $(z=5.08, p<.001)$ and between adolescent report of low self-control and risky sex $(z=$ $2.05, p<.05)$. Wave 3 self-control mediated the relationship between parent report of low self-control $(z=2.30$, $p<.05)$ and adolescent report of low self-control $(z=$ $2.31, p<.05)$ with risky sexual behaviors. In the model of only male participants, early sex mediated the relationships between parent report of low self-control $(z=2.92$, $p<.01)$ and adolescent report of low self-control $(z=$ $3.04, p<.01)$ with risky sexual behaviors. Wave 3 selfcontrol also mediated the relationships between baseline parent report of low self-control $(z=1.99, p<.05)$ and baseline adolescent report of low self-control $(z=3.15$, $p<.01)$.

There was evidence of moderation in the male-only model $(-0.26, p<.01)$, but not in the female-only model. Given these results, the mediation model appears most appropriate for females (Fig. 3) and the model that includes an interaction term is most appropriate for males (Fig. 4).

\section{Discussion}

Approximately $17 \%$ of adolescents in our sample reported being less than 15 years of age at first sexual intercourse. This is similar to estimates from other national samples $[4,6]$. Consistent with our hypotheses, we observed that low self-control was associated with early 
Table 1 Descriptive Characteristics

\begin{tabular}{|c|c|c|c|}
\hline & Total $(n=5734)$ & Male $(n=2702)$ & Female $(n=3032)$ \\
\hline \multirow[t]{2}{*}{ Age in years M (SD) } & $16.0(1.75)$ & $16.1(1.75)$ & $15.9(1.74)$ \\
\hline & n (\%) & & \\
\hline \multicolumn{4}{|l|}{ Race/Ethnicity } \\
\hline White Alone & $3352(58.46)$ & $1593(58.96)$ & $1759(58.01)$ \\
\hline Black Alone or with any other race & $1394(24.31)$ & $631(23.35)$ & $763(25.16)$ \\
\hline Hispanic & $623(10.87)$ & $296(10.95)$ & $327(10.78)$ \\
\hline Other, Non-Hispanic & $365(6.37)$ & $182(6.74)$ & $183(6.04)$ \\
\hline \multicolumn{4}{|l|}{ Relationship Status in Wave 4} \\
\hline Married & $2162(37.70)$ & $885(32.75)$ & $1277(42.12)$ \\
\hline Cohabitating & $1003(17.49)$ & $475(17.58)$ & $528(17.41)$ \\
\hline Dating & $793(13.83)$ & $430(15.91)$ & $363(11.97)$ \\
\hline Single & $535(9.33)$ & $265(9.81)$ & $270(8.91)$ \\
\hline \multicolumn{4}{|l|}{ Wave 1 Socioeconomic Risk } \\
\hline 0 Risks & $2997(60.67)$ & $1422(60.72)$ & $1575(60.64)$ \\
\hline 1 Risk & $1429(28.93)$ & $685(29.25)$ & $744(28.65)$ \\
\hline 2 Risks & $403(8.16)$ & $188(8.03)$ & $215(8.27)$ \\
\hline 3 Risks & $110(2.23)$ & $47(2.01)$ & $63(2.43)$ \\
\hline \multicolumn{4}{|l|}{ Wave 4 Socioeconomic Risk } \\
\hline 0 Risks & $1618(31.94)$ & $704(30.27)$ & $914(33.36)$ \\
\hline 1 Risk & $2386(47.10)$ & $1158(49.82)$ & $1228(44.81)$ \\
\hline 2 Risks & $904(17.84)$ & $386(16.60)$ & $518(18.91)$ \\
\hline 3 Risks & $157(3.10)$ & $77(3.31)$ & 80 (2.92) \\
\hline \multicolumn{4}{|l|}{ Age at First Intercourse } \\
\hline Early Age (< 15 years) & $954(16.64)$ & 459 (16.99) & $495(16.33)$ \\
\hline Normative Age ( $\geq 15$ years) & $4780(83.36)$ & $2537(83.67)$ & $2537(83.67)$ \\
\hline
\end{tabular}

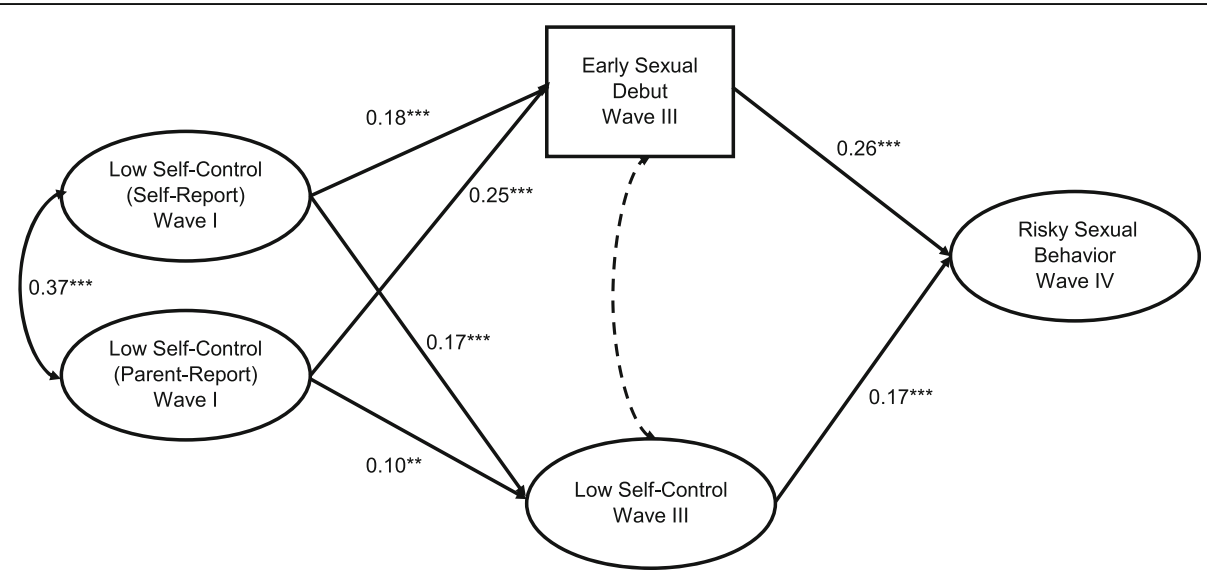

Fig. 1 Mediation Model for the relationship between self-control, impulsivity, early sexual debut and risky sexual behavior among male and female respondents to Add Health, $n=5734 .{ }^{*} p<.05,{ }^{* *} p<.01,{ }^{* * *} p<.001$, Model Fit: RMSEA: 0.03; CFI: 0.92; Model Controls for DIF. Dotted line indicates non-significant relationship. Indirect Paths: Low Self Control (Self-Report) $\rightarrow$ Early Sexual Debut $\rightarrow$ Risky Sexual Behavior: $z=4.14, p<.001$, Low Self Control (Parent Report) $\rightarrow$ Early Sexual Debut $\rightarrow$ Risky Sexual Behavior: $z=6.07, p<.001$, Low Self Control (Self-Report) $\rightarrow$ Impulsivity $\rightarrow$ Risky Sexual Behavior: $z=4.16, p<.001$, Low Self Control (Parent Report) $\rightarrow$ Impulsivity $\rightarrow$ Risky Sexual Behavior: $z=3.54, p<.001$ 


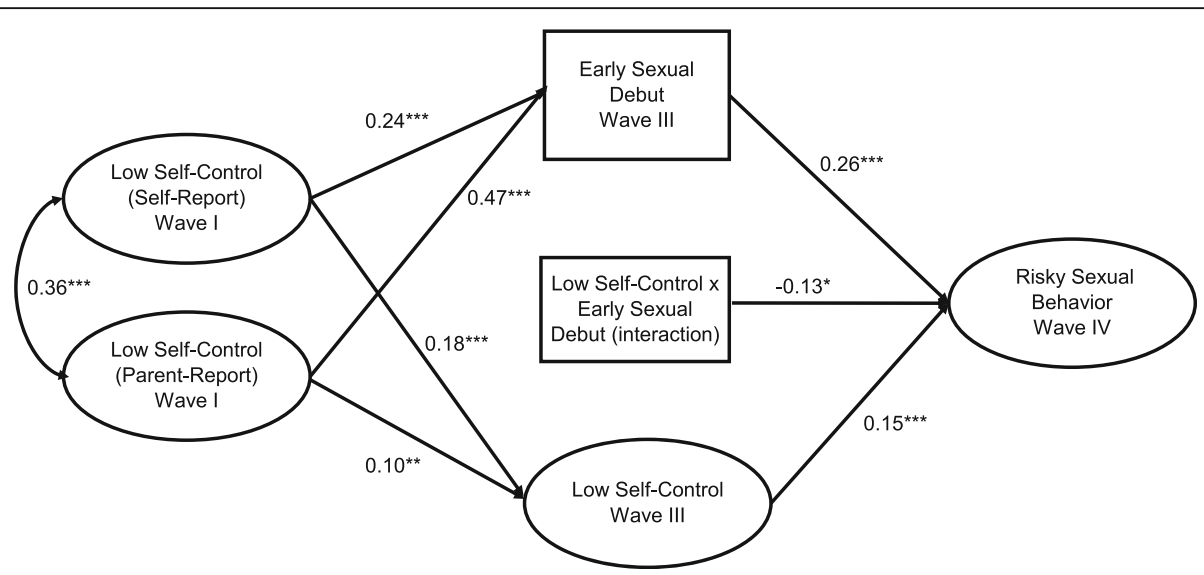

Fig. 2 Moderation Model for the effect of impulsivity and early sexual debut on risky sexual behavior among male and female respondents to Add Health, $\mathrm{n}=5734 .{ }^{*} p<.05,{ }^{* *} p<.01,{ }^{* *} p<.001$. Model Controls for DIF

sexual debut, supporting the idea that low self-control in early adolescence at least partially explains selection into early sexual debut. Further, we observed that wave 3 low self-control was associated with risky sexual behavior in young adulthood. Additionally, the finding that low selfcontrol was persistent across time with wave 1 selfcontrol being predictive of wave 3 self-control further supports the contribution of adolescent low self-control on risky sexual behavior in adulthood. This suggests that interventions targeting self-control may be influential in delaying entry into sexual intercourse and reducing participation in risky sexual behaviors in adulthood among those with early debut.

Mental contrasting is a learnable skill that helps adolescents visualize their goals; identify potential barriers to reaching these goals, and to develop a plan to overcome these barriers thus increasing self-control. Interventions focusing on capacity building for self-control, such as mental contrasting training, may be effective in helping young adolescents delay entry into sexual activity and/or avoid risky sexual behaviors in adulthood. Duckworth and colleagues found that adolescents who received training on mental contrasting were better able to complete highstakes tests compared to their peers who did not receive this training. Relating this to early sexual debut and selfcontrol, adolescents who learn mental contrasting may be better able to resist sex in high-pressure social situations if they have first formulated a goal to delay sex and a plan for overcoming likely obstacles [29].

In males, higher self-control strengthened the relationship between early sex and risky sex, which was the opposite of what we expected. This may be due to

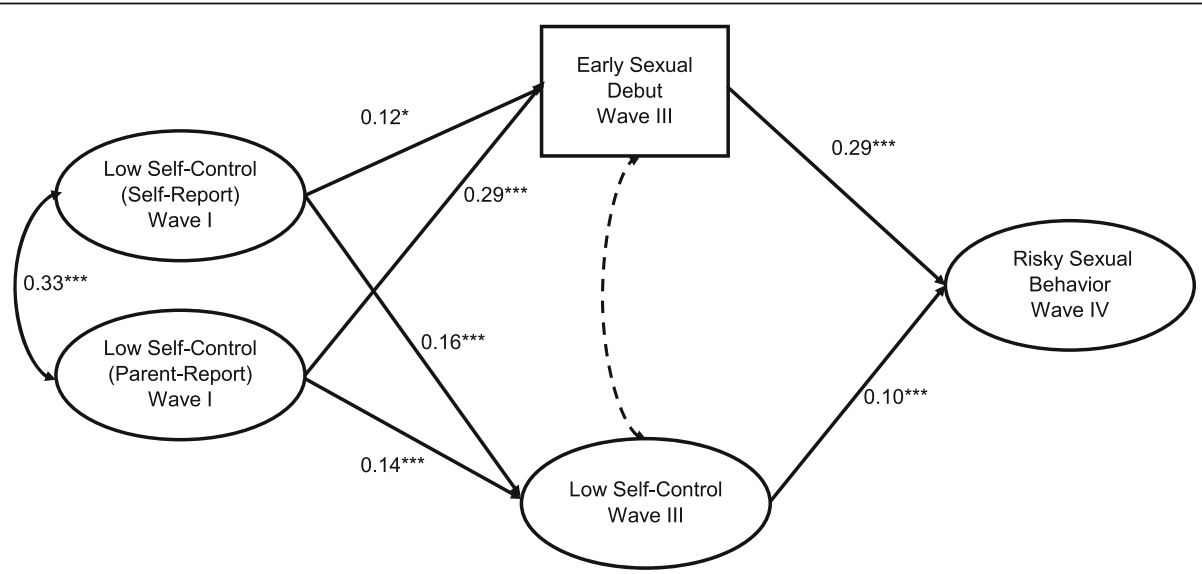

Fig. 3 Mediation Model for the relationship between self-control, impulsivity, early sexual debut and risky sexual behavior, among female respondents to Add Health, $n=3032 .{ }^{*} p<.05,{ }^{* *} p<.01,{ }^{* * *} p<.001$, Model Fit: RMSEA: 0.02; CFI: 0.94, Model Controls for DIF. Dotted line indicates non-significant relationship. Indirect Paths: Low Self Control (Self-Report) $\rightarrow$ Early Sexual Debut $\rightarrow$ Risky Sexual Behavior: $z=2.05, p<.05$. Low Self Control (Parent Report) $\rightarrow$ Early Sexual Debut $\rightarrow$ Risky Sexual Behavior: $z=5.08, p<.001$. Low Self Control (Self-Report) $\rightarrow$ Impulsivity $\rightarrow$ Risky Sexual Behavior: $z=2.31, p<.01$. Low Self Control (Parent Report) $\rightarrow$ Impulsivity $\rightarrow$ Risky Sexual Behavior: $z=2.30, p<.01$ 


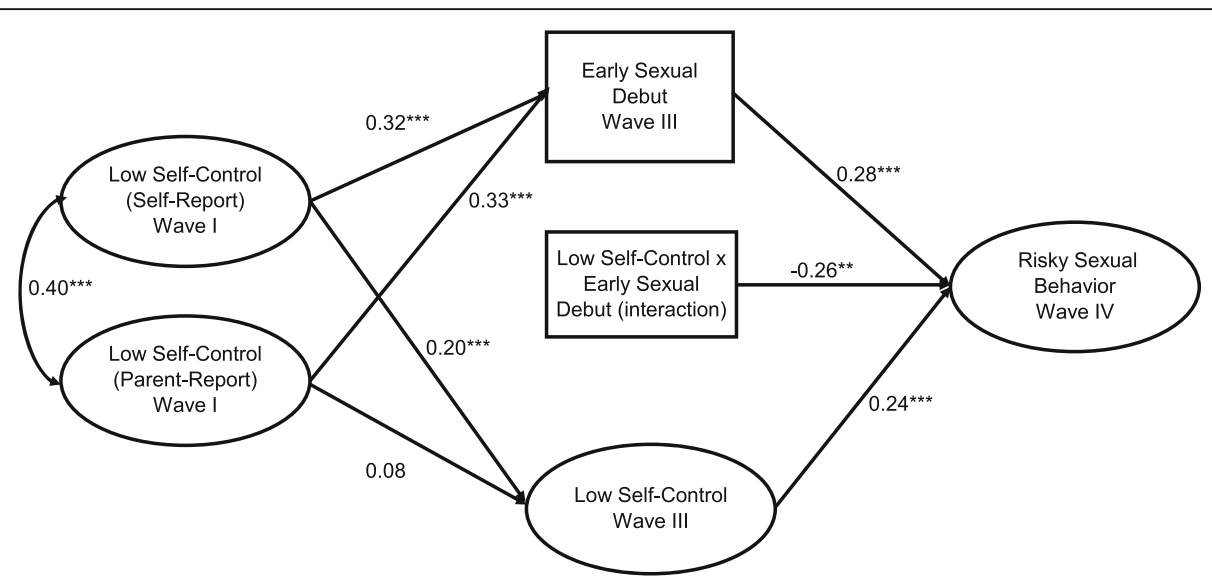

Fig. 4 Moderation Model for the effect of impulsivity and early sexual debut on risky sexual behavior among male respondents to Add Health, $n=2702 .{ }^{*} p<.05,{ }^{* *} p<.01,{ }^{* * *} p<.001$. Model Controls for DIF

differences in behavioral expectations surrounding sex between males and females. Sexual script theory [16] identifies gendered prescriptions for socially acceptable sexual behavior. Sexual scripts are generally thought to promote a higher level of sexual activity in males than in females resulting in relatively higher social costs for sexually active females and relatively higher social rewards for sexually active males [18]. Given these sexual scripts, it may be that young adult males with low selfcontrol are more likely to participate in risky sexual behavior regardless of their timing of sexual debut.

These data should be considered with several caveats. This study relies on self-report measures for self-control, early sex and risky sex. Self-report of executive functions such as self-control may be biased. The use of parental reports where available may reduce bias in the study introduced by self-report of self-control. Previous research has acknowledged the challenge of accurately measuring sexual behavior [30, 31]. We acknowledge that the use of biological age at sexual debut is limited and does not consider important issues related to sexual readiness [32]. Further, questions about sexual initiation in Add Health are specific to vaginal intercourse and therefore do not appropriately represent participation in other sexual behaviors, including among those without opposite-sex sexual experience. As such, the results of this study cannot be applied to those who identify as non-heterosexual. The gender-specific models in this paper are based on biological sex and likely do not represent persons who are transgender or have a nonbinary gender identity. The use of two different measures of self-control in waves 1 and 3 may have introduced measurement error. Further, we acknowledge the possibility that sexual debut for some respondents may have occurred prior to our wave 1 measures of selfcontrol. Our measures of risky sexual behavior in wave 4 was limited to the three questions available in the data and as such, does not capture all forms of risky sexual behavior.

Despite these limitations, this study has a number of strengths. The use of a longitudinal sample stands in contrast to most studies of early sex and risky sex, which have relied on cross-sectional data. The data were analyzed using structural equation modeling which accounts for measurement error and provides an ideal forum for examining mediation and moderation. Finally, the national representative $A d d$ Health sample allows wide generalizability of the findings of this study.

\section{Conclusion}

This study adds to the body of literature suggesting the role of executive functions such as self-control in sexual behaviors including early sexual debut and risky sexual behavior in adulthood. Previous research suggests that interventions may be useful in increasing executive function, which may have an impact in delaying sexual debut or ensuring that the timing of sexual debut is developmentally appropriate for individuals based on social and emotional readiness and reducing participation in risky sexual behaviors in young adulthood.

\section{Abbreviations \\ CFA: Confirmatory factor analysis; CFI: Comparative fit index; DIF: Differential item functioning; FIML: Full information maximum likelihood; RMSEA: Root mean square error of approximation; SCT: Social cognitive theory; \\ SEM: Structural equation modelling; STD: Sexually transmitted disease}

\section{Acknowledgements \\ None.}

\section{Authors' contributions}

BM conceived of the study, assisted with the analysis and is primarily responsible for the written manuscript. AC conducted the analysis and contributed to the manuscript. KE participated in data preparation and manuscript preparation. All authors have approved the final manuscript. 


\section{Funding}

This work was supported by a Women's Research Initiative Grant from Brigham Young University.

\section{Availability of data and materials}

The data used in this study is publicly available at: https://www.cpc.unc.edu/ projects/addhealth/

\section{Ethics approval and consent to participate}

IRB approval was waived for this study utilizing de-identified publicly available data. Participants in the Add Health dataset participated in an informed consent process during the data collection.

\section{Consent for publication}

Not Applicable.

\section{Competing interests}

The authors declare that they have no competing interests.

Received: 10 January 2019 Accepted: 9 October 2019

Published online: 08 November 2019

\section{References}

1. Martinez GM, Abma JC. Sexual activity, contraceptive use, and childbearing teenagers aged 15-19 in the United States. NCHS Data Brief No. 209. 2015 Available at: https://www.cdc.gov/nchs/products/databriefs/db209.htm

2. Kaestle CE, Halpern CT, Miller WC, Ford CA. Young age at first sexual intercourse and sexually transmitted infections in adolescents and young adults. Am J Epidemiol. 2005;161(8):774-80.

3. Santelli JS, Brener ND, Lowry R, Bhatt A, Zabin LS. Multiple sexual partners among U.S. adolescents and young adults. Fam Plan Perspect. 1998;30(6): 271-5.

4. Magnusson BM, Masho SW, Lapane KL. Early age at first intercourse and subsequent gaps in contraceptive use. J Women's Health. 2012;21(1):73-9. https://doi.org/10.1089/jwh.2001.2893.

5. Magnusson BM, Masho SW, Lapane KL. Adolescent and sexual history factors influencing reproductive control among US women aged 18-44. Sex Health. 2011;8(1):95-101. https://doi.org/10.1071/SH10007.

6. Magnusson BM, Nield JA, Lapane KL. Age at first intercourse and subsequent sexual partnering among adult women in the United States, as cross-sectional study. BMC Public Health. 2015;15:98.

7. Finer LB, Philbin JM. Sexual initiation, contraceptive use, and pregnancy among young adolescents. Pediatrics. 2013;131(5):886-91.

8. Cavazos-Rehg PA, Krauss MJ, Spitznagel EL, Schootman M, Bucholz KK Peipert JF, Sanders-Thompson V, Cottler LB, Bierut LJ. Age of sexual debut among US adolescents. Contraception. 2009;80(2):158-62.

9. Khurana A, Romer D, Betancourt LM, Brodsky NL, Giannetta JM, Hurts H. Early adolescent sexual debut: the mediating role of working memory ability, sensation seeking, and impulsivity. Dev Psychol. 2012;48(5):1416-28. https://doi.org/10.1037/a0027491.

10. Dir AL, Coskunpinar A, Cyders MA. A meta-analytic review of the relationship between adolescent risky sexual behavior and impulsivity across gender, age, and race. Clin Psychol Rev. 2014;34(7):551-62. https://doi.org/10.1016/j.cpr2014.08.004.

11. Curry I, Luk JW, Trim RS, Hopfer CJ, Hewitt JK, Stallings MC, Brown SA, Wall TL. Impulsivity dimensions and risky sex behaviors in an at-risk young adult sample. Arch Sex Behav. 2018;41(2):529-36. https://doi.org/10.1007/s/10508017-1054-x.

12. Blakemore SJ, Choudhury S. Development of the adolescent brain: implications for executive function and social cognition. J Child Psychol Psychiatry. 2006;47(3-4):296-312 Review

13. Shulman EP, Harder KP, Chein JM, Steinberg L. Sex differences in the developmental trajectories of impulse control and sensation-seeking from early adolescence to early adulthood. J Youth Adolesc. 2015;1:1-17. https://doi.org/10.1007/s10964-017-0116-9.

14. Chapple $\mathrm{CL}$, Johnson KA. Gender differences in impulsivity. Youth Violence Juv Justice. 2007:5(3):221-34

15. Stoltenberg SF, Batien BD, Birgenheir DG. Does gender moderate associations among impulsivity and health-risk behaviors. Addictive Beh. 2008;33(2):252-65
16. Simon W, Gagnon JH. Sexual scripts: origins, Influences and Changes. Qual Soc. 2003;26(4):491-7.

17. Widerman MW. The gendered nature of sexual scripts. The Family J. 2005; 13(4):496-502.

18. Kreager DA, Staff J, Gauthier LES, Feinberg ME. The double standard at sexual debut: gender, sexual behavior and adolescent peer acceptance. Sex Roles. 2016;75(7):377-92. https://doi.org/10.1007/s11199-016-0618-x.

19. Maas MK, Shearer CL, Gillen MM, Lefkowitz ES. Sex rules: emerging adults' perceptions of gender's impact on sexuality. Sex Cult. 2015;19(4):617-36.

20. Bandura A. Social cognitive theory of self-regulation. Organ Behav Hum Decis Process. 1991;50(2):248-87.

21. Harris KM. The add health study: design and accomplishments. 2013. Available at: http://www.cpc.unc.edu/projects/addhealth/documentation/ guides/DesignPaperWIIV.pdf. Accessed Dec 62017.

22. Beaver KM, Ratchford M, Ferguson CJ. Evidence of genetic and environmental effects on the development of low self-control. Crim Justice Behav. 2009;36(11):1158-72.

23. Gómez AM, Speizer IS, Reynolds H, Murray N, Beauvais H. Age differences at sexual debut and subsequent reproductive health: Is there a link. Reprod Health. 2008:5:8.

24. O'Donnell L, O'Donnell CR, Stueve A. Early sexual initiation and subsequent sex-related risks among urban minority youth: the reach for health study. Fam Plan Perspect. 2001;33(6):268-75

25. Hu L, Bentler PM. Cutoff criteria for fit indexes in covariance structure analysis: conventional criteria versus new alternatives. Struct Equ Modeling 1999;6(1):1-55.

26. Preacher KJ, Hayes AF. Asymptotic and resampling strategies for assessing and comparing indirect effects in multiple mediator models. Behav Res Methods. 2008;40(3):879-91.

27. Holland PW, Thayer DT. Differential item performance and the mantelHaenszel procedure. In: Wainer $\mathrm{H}$, Braun $\mathrm{HI}$, editors. Test validity. Hillsdale: Lawrence Erlbaum Associates Inc; 1988.

28. Clauser BE, Mazor KM. Using statistical procedures to identify differentially functioning test items. Educ Meas Issues Pract. Spring 1998:31-44. https:// doi.org/10.1111/j.1745-3992.1998.tb00619.x.

29. Duckworth AL, Grant H, Loew B, Oettingen G, Gollwitzer PM. Self-regulation strategies improve self-discipline in adolescents: benefits of mental contrasting and implementation intentions. Educ Psychol. 2011;31(1):17-26.

30. Minnis AM, Steiner MJ, Gallo MF, Warner L, Hobbs MM, van der Straten A, et al. Biomarker validation of reports of recent sexual activity: results of a randomized controlled study in Zimbabwe. Am J Epidemiol. 2009;170(7): 918-24

31. Fenton KA, Johnston AM, McManus S, Erens B. Measuring sexual behavior: methodological challenges in survey research. Sex Transm Infect. 2001;77(2): 84-92.

32. Hawes ZC, Wellings K, Stephenson J. First heterosexual intercourse in the United Kingdom: a review of the literature. J Sex Res. 2010;47:137-52.

\section{Publisher's Note}

Springer Nature remains neutral with regard to jurisdictional claims in published maps and institutional affiliations.
Ready to submit your research? Choose BMC and benefit from:

- fast, convenient online submission

- thorough peer review by experienced researchers in your field

- rapid publication on acceptance

- support for research data, including large and complex data types

- gold Open Access which fosters wider collaboration and increased citations

- maximum visibility for your research: over $100 \mathrm{M}$ website views per year

At $\mathrm{BMC}$, research is always in progress.

Learn more biomedcentral.com/submissions 